\title{
Faktor yang Berhubungan dengan Motivasi Ibu untuk Melakukan Kunjungan ANC di Puskesmas Cibadak Desa Malabar
}

\author{
Tia Irmaya ${ }^{1}$, Jesy Fatimah ${ }^{2}$ \\ ${ }^{1,2}$ Program Studi Kebidanan Program Sarjana Terapan Sekolah Tinggi Ilmu Kesehatan Indonesia Maju \\ Jln.Harapan Nomor 50, Lenteng Agung-Jakarta Selatan 12610. Indonesia \\ Telp: (021)78894045,Email: tiairmaya819@gmail.com'; jesybph@yahoo.com²
}

\begin{abstract}
Abstrak
Motivasi ibu dalam melakukan kunjungan (antenatal care) ANC trimester III sekurang-kurangnya 2 kali jika pemeriksaan tidak dilakukan akan beresiko, untuk deteksi dini dan penanganan komplikasi. Beberapa faktor dalam pencegahan terjadinya resiko motivasi ibu hamil seperti kelas ibu hamil, tingkat ekonomi, tempat fasilitas kesehatan. Tujuan penelitian untuk mengetahui hubungan kelas ibu hamil, tingkat ekonomi, dan tempat fasilitas kesehatan terhadap motivasi ibu hamil dalam melakukan kunjungan ANC di Puskesmas Cibadak Desa Malabar tahun 2017. Desain penelitian analitik kuantitatif pendekatan cross sectional, data primer, teknik sampling yang digunakan $50 \mathrm{ibu}$ hamil. Hasil penelitian sebagian besar di Puskesmas Cibadak diperoleh responden yang memiliki motivasi rendah sebanyak (52,0\%), ibu hamil yang tingkat ekonomi < 1 juta sebanyak $(62,0 \%)$, tempat fasilitas kesehatan yang buruk sebanyak (54,0\%), Analisis bivariat dengan uji Chi Square menunjukan bahwa ada hubungan signifikan antara kelas ibu hamil dengan motivasi ibu hamil $p$ value $(0,000)$, terdapat hubungan signifkan antara tingkat ekonomi dengan ibu hamil $p$ value $(0,001)$, sehingga dapat disimpulkan bahwa ada hubungan yang signifikan antara tempat fasilitas kesehatan dengan motivasi ibu hamil. kesimpulan bahwa terdapat hubungan kelas ibu hamil, tingkat ekonomi, dan tempat fasilitas kesehatan terhadap motifasi ibu hamil dalam melakukan kunjungan ANC. Saran ibu hamil dalam melakukan kunjungan ANC lebih ditingkatkan untuk mengikuti kelas ibu hamil.
\end{abstract}

Kata Kunci $\quad$ : Kelas Ibu Hamil, Tingkat Ekonomi, Tempat Fasilitas Kesehatan

\begin{abstract}
Abstrak
Maternal motivation in ANC visit for third trimester at least 2 times the examination during pregnancy. Standard time of service is to ensure protection of mother or fetus, in the form of early detection of risk factors, prevention and treatment of complications. A pregnant woman is said to be at risk if an ANC visit is not performed in accordance with the third trimester that should be 2 times the examination in pregnancy. Several risk factors are thought to have a role in preventing the risk of pregnant women's motivations such as pregnant women's classes, economic levels and health facilities. The purpose of this research is to know the relationship of maternal class, economic level, and place of health facility to motivation of pregnant mother in doing ANC visit at Puskesmas Cibadak Desa Malabar 2017. This research design is quantitative analytical with cross sectional approach, primary data, total sampling 50 pregnant mother. The results of most of the research in cibadak clinic of malabar village were obtained by respondents who have low motivation as much as (52,0\%), it is known that pregnant woman with economic level $<1$ million as much (62,0\%), 54,0\%), bivariate analysis with Chi Square test shows that there is a significant correlation between maternal class with pregnant mother motivation $p$ value (0.000), there is significant correlation between economic level with pregnant woman $p$ vallue $(0,001)$ it was concluded that there is a significant relationship between health facility and maternal motivation. the conclusion that there is a relationship of maternity class, economic level, and place of health facility to motivation of pregnant.
\end{abstract}

Keywords : Pregnancy Class, Economic Level, Health Facility Place 


\section{Pendahuluan}

Asuhan antenatal adalah pemeriksaan kehamilan untuk melihat dan memeriksa keadaan ibu dan janin yang dilakukan secara berkala diikuti dengan upaya koreksi terhadap penyimpangan yang ditemukan selama kehamilan. Asuhan antenatal pengawasan sebelum persalinan terutama ditunjukan pada pertumbuhan dan perkembangan janin dalam rahim. Frekuensi pelayanan antenatal minimal 1 kali pada trimester pertama, trimester ketiga minimal 2 kali. ${ }^{1}$

Dalam pemeliharaan dan pengawasan antenatal care sedini mungkin, serta persalinan yang aman dan perawatan masa nifas yang baik adalah upaya yang dilakukan untuk mengendalikan angka kematian ibu dan bayi. Didalam kehamilan diperlukan pengawasan dan pemeriksaan secara teratur atau dikenal dengan antenatal care (ANC). Menurut world health organization (WHO) sebanyak 536.000 Perempuan meninggal akibat persalinan, sebanyak $99 \%$ kematian ibu akibat masalah persalinan atau kelahiran terjadi di Negara-negara berkembang rasio kematian-kematian ibu di Negara berkembang merupakan data tahun 2012 tertinggi dengan 450 kematian ibu per 100.000 kelahiran bayi hidup jika dibandingkan dengan rasio kematian ibu di 9 negara maju dan 51 negara persemakmuran. Idealnya bila setiap wanita hamil ingin memeriksakan kehamilannya, bertujuan untuk mendeteksi kelainan-kelainan yang mungkin akan terjadi dan segera dapat diatasi sebelum berpengaruh tidak baik terhadap kehamilannya dengan melakukan pemeriksaan antenatal care. ${ }^{2}$

Setiap masa kehamilan, dalam perkembangannya akan mempunyai risiko mengalami penyulit atau komplikasi. Oleh karena itu, pelayanan antenatal care harus dilakukan secara rutin, sesuai standar dan terpadu untuk pelayanan antenatal yang berkualitas. $^{3}$

\footnotetext{
Hasil riset kesehatan dasar (Riskesdas) yang dilakukan Kementrian Kesehatan memperlihatkan bahwa data cakupan antenatal care di Indonesia selama periode 3 tahun terakhir pada tahun 2010, 2013 - 2014 yaitu tahun 2010 sebesar 84,38\% untuk kunjungan 1 , dan kunjungan 4 sebesar $85,56 \%$. Untuk tahun 2013 sebesar 90,88\%. Hasil pencapaian cakupan pelayanan K1 Indonesia tahun 2014
}

sebesar 94,99\% dan K4 sebesar 86,70. Secara Nasional indikator kinerja cakupan pelayanan ibu hamil K4 pada tahun 2014 belum mencapai target Rencana Strategis (Renstra) Kementrian Kesehatan tahun 2014, yakni sebesar 95\%.

Menurut data Dinas Kesehatan Provinsi Banten Tahun 2014, cakupan K1 di Provinsi Banten tahun 2013 yaitu 97,1\% dan cakupan K4 yaitu $86,2 \%$. Target Nasional pada tahun 2015 harus dicapai adalah K1 95\% dan K4 90\%. ${ }^{5}$ Cakupan ANC di Kabupaten Rangkasngbitung tahun 2013 yaitu K1 81, $65 \%$ dan K4 yaitu 69, 53\%. Cakupan K1 dan K4 Kabupaten Serang belum mencapai target Nasional yaitu 95\% untuk K1 dan 90\% untuk target K4. Wilayah kerja Puskesmas Cibadak Desa Malabar merupakan salah satu Puskesmas di Kabupaten Kota Rangkasbitung yang mencakup 15 Desa dan memiliki 60 Posyandu. Berdasarkan laporan hasil kegiatan program KIA Puskesmas Cibadak tahun 2015, cakupan pelayanan ANC yaitu K1 95\% dan K4 91, 9\%. Target pelayanan $\mathrm{K} 1$ dan $\mathrm{K} 4$ pada tahun 2015 yaitu 75\%. Cakupan K1 sudah mencapai target, tetapi cakupan $\mathrm{K} 4$ belum mencapai target Nasional. ${ }^{5}$

Salah satu dalam masalah kesehatan dalam kehamilan yaitu rendahnya motivasi ibu hamil melakukan kunjungan antenatal care (ANC), ada beberapa faktor yang menjadi penyebab yang mempengaruhi ibu hamil kurang termotivasi dalam melakukan ANC secara teratur dan tepat waktu antara lain : Kurangnya pengetahuan ibu hamil tentang ANC, kesibukan, tingkat sosial ekonomi yang rendah, dukungan suami yang kurang, kurangnya kemudahan untuk pelayanan maternal, asuhan medik yang kurang baik, kurangnya tenaga terlatih dan obat penyelamat jiwa. $^{6}$

Jika motivasi ibu hamil dalam kunjungan ANC tidak segera dilakukan akan menyebabkan ibu dan bayi tidak terdeteksi secara dini dan mencegah pada K4 untuk mengurangi kematian ibu (AKI), maupun angka kematian bayi (AKB). Sedangkan dalam kehamilan kita harus melakukan kunjungan ANC dari trimester I minimal 1 kali, trimester II minimal 1 kali, trimester III minimal 2 kali. $^{7}$

Motif dari Bahasa latin movere yang berarti begerak. Motif diartikan sebagai kekuatan yang terdapat dalam organisme hal ini manusia yang mendorong untuk berbuat 
sesuatu atau merupakan driving force. Tindakan manusia dipengaruhi faktor dari luar dan dari dalam. ${ }^{8}$ Beberapa Astuti febiana mustofa faktor lainnya yang menunjukan hubungan tingkat ekonomi didapatkan hasil analisis dengan menggunakan chi-square dengan taraf kepercayaan 95\%, $p$ value 0,025 ( $p$ value $<0,005)$ contingency coefficient $(\mathrm{cc})$ sebesar $0,468{ }^{9}$

Berdasarkan hasil penelitian ini sesuai dengan Diah Rahayu, di dapatkan hasil analisis dengan uji chi square, $\rho$ value 0,033 ( $\rho$ value $<0,005)$, sehingga dapat disimpulkan ada hubungan yang bermakna antara tempat fasilitas kesehatan dengan komitmen kerja bidan. $^{10}$

Berdasarkan hasil penelitian ini sejalan dengan penelitian Hj. Erni Setiawati, M Mukhtar, dkk. Maslani di dapat hasil uji ChiSquare pada $(\alpha) 0,05, \rho$ value $=0,001$ atau lebih kecil dari $(\alpha)$ sehingga Ho ditolak, artinya ada hubungan antara kelas ibu hamil terhadap pelaksanaan senam hamil. ${ }^{11}$

Berdasarkan hasil pengkajian awal di Puskesmas Cibadak Desa Malabar pada tanggal 3 Juni 2017 , ke pada 10 ibu hamil terdapat $5 \mathrm{ibu}$ hamil yang tidak bisa mengikuti kelas ibu hamil karena banyak pekerjaan dirumahnya, lalu terdapat 3 ibu hamil yang mengatakan tidak rutin melakukan kunjungan ANC karena ekonomi yang terbatas sehingga tidak bisa melengkapi kunjungan ANC nya, dan 2 ibu hamil mengatakan bahwa tempat fasilitas kesehatan yang jauh sehingga menurunkan motivasi ibu tersebut untuk melakukan ANC.

Tujuan penelitian ini adalah untuk mengetahui hubungan kelas ibu hamil, Tingkat ekonomi, dan Tempat fasilitas kesehatan terhadap motivasi ibu hamil dalam melakukan kunjungan ANC di Puskesmas Cibadak Malabar tahun 2017.

\section{Metode}

Jenis penelitian ini menggunakan metode penelitian survey dengan pendekatan kuantitatif, dengan desain penelitian cross sectional. Desain studi cross sectional yaitu suatu penelitian dimana mengukur variabel bebas dan variabel terikat yang di kumpulkan dalam waktu yang bersamaan dalam satu sampel populasi. ${ }^{12}$
Metode pengumpulan data merupakan cara yang dapat digunakan oleh penelitian untuk mengumpulkan data dengan mempelajari dokumentasi-dokumentasi atau catatan-catatan yang menunjang penelitian yang sedang dilakukan. Tekhnik pengumpulan data ini terdiri dari sifat dan sumber data pengelohan data. Populasi diartikan sebagai wilayah generalisasi yang terdiri atas: Obyek/ Subyek yang mempunyai kualitas dan karakteristik tertentu yang ditentukan oleh peneliti untuk dipelajari dan kemudian ditarik kesimpulan. Populasi dalam penelitian ini berjumlah 50 ibu hamil di Puskesmas Cibadak Desa Malabar. ${ }^{12}$

Sampel adalah sebagian dari populasi itu. Populasi itu misalnya penduduk di wilayah tertentu, jumlah pegawai pada organisasi tertentu, jumlah guru dan murid di sekolah tertentu dan sebagainya. ${ }^{13}$ Dalam penelitian ini menggunakan total sampling yang masih relative kecil, hanya satu tempat penelitian, dan serta tidak membutuhkan waktu yang cukup banyak. Seluruh jumlah populasi dijadikan sebagai responden berjumlah $30 \mathrm{ibu}$ hamil. Dalam penelitian ini menggunakan total sampling yang masih relative kecil, hanya satu tempat penelitian, dan serta tidak membutuhkan waktu yang cukup banyak. Seluruh jumlah populasi dijadikan sebagai responden berjumlah 30 ibu hamil. Populasi dalam penelitian ini berjumlah 50 ibu hamil di Puskesmas Cibadak Desa Malabar.

Syarat pengambilan sampel agar karakteristik sampel tersebut tidak menyimpang dari populasinya, perlu juga ditentukan kriteria inklusi maupun eksklusi. Kriteria inklusi adalah karakteristik umum subjek penelitian ini dari suatu populasi target yang terjangkau yang akan di teliti. Peneliti menjelaskan sebelum membagikan kuesioner tata cara pengisian kepada responden dan menunggu sampai responden selesai mengisi kuesioner yang telah diberikan.

Kreteria inklusi yaitu Ibu hamil di Puskesmas Cibadak Desa Malabar yang bersedia menjadi responden dan mengisi kuesioner, Ibu hamil di Puskesmas Cibadak Desa Malabar yang bersedia menjadi responden dan mengisi kuesioner, hamil yang hadir dan bersedia di Puskesmas Cibadak Desa Malabar, Ibu hamil Trimester III di Puskesmas Cibadak Desa Malabar yang bersedia menjadi 
responden. Non inklusi karakteristik umum subjek penelitian ini dari suatu populasi target yang terjangkau yang akan di teliti yaitu Ibu hamil bersedia menjadi responden dan mengisi quisioner, dan Ibu hamil yang hadir datang ke Puskemas Cibadak Desa Malabar. ${ }^{14}$

Kriteria eksklusi adalah yang tidak sesuai karakteristik umum subjek penelitian dari suatu populasi target yang terjangkau yang akan di teliti. Uji coba instrumen harus diuji coba untuk mengetahui apakah instrumen tersebut valid dan apakah instrumen tersebut reliabilitas. Dalam penelitian ini penguji validitas instrument menggunakan pengolahan SPSS 18. Instrumen harus diuji coba untuk mengetahui apakah instrumen tersebut valid dan apakah instrumen tersebut reliabilitas. Menurut pendapat Arikunto dalam buku Penelitian Kuantitatif, validitas adalah suatu ukuran yang menunjukan tingkat-tingkat kevalidan atau kesahan suatu instrument. Suatu instrument yang valid atau sah mempunyai validitas tinggi Sebaliknya instrument yang kurang valid berarti memiliki validitas rendah. ${ }^{14}$ Uji validitas dalam penelitian ini menggunakan rumus Pearson Product Momment. Hasil uji validitas dengan menggunakan rumus yang sudah ditetapkan $\mathrm{df}$ $=\mathrm{n}-2$, sehingga didapatkan $32-2=30$ pada $\mathrm{r}$ tabel $=0,349$ dan data yang diperoleh yaitu 36 item pernyataan valid. Hasil uji coba reliabilitas instrumen dilakukan terhadap 32 responden. Apabila nilai $\mathrm{r}$ Alpha $>\mathrm{r}$ Tabel $(0,349)$ maka pernyataan tersebut reliabel. ${ }^{15}$

Dari 52 item pernyataan didapatkan koefisien $\alpha$ 0,908 (Motivasi Ibu), 0,855 (Kelas Ibu Hamil), 0,832 (Tingkat Ekonomi), 0,822 (Tempat Fasilitas Kesehatan) sehingga ke 36 item pernyataan dinyatakan reliabel. Proses pengumpulan data dilakukan setelah penelitian mendapatkan izin dari instansi terkait yang ditunjukan kepada tempat peneliti yaitu Puskesmas Cibadak Desa Malabar Tahun 2017. Dalam penelitian ini instrumen yang berupa kuesioner dibagikan dan di isi langsung oleh responden. Data kemudian di input atau di entri. Coding Mengubah data (jawaban

responden) berbentuk kata-kata menjadi data angka atau bilangan. Pemberian kode beguna memasukan data (data entry). Cleaning setelah semua data selesai dimasukan, perlu dicek kembalikan untuk melihat kemungkinan adanya kesalahan kode, kemungkinan ada data yang hilang dan mengecek konsistensi data (menghubungkan 2 variabel). Checking Upaya untuk memeriksa kembali kebenaran data yang diperoleh atau dikumpulkan. Data bersih Setelah di cleaning tidak ada (kuesioner) yang terisi, kemudian dengan menggunakan coding atau pengkodean agar data bisa dimasukkan ke dalam SPSS untuk pengolahan data.

Analisis Penelitian Data yang diolah menggunakan software SPSS versi 18 yang hasilnya meliputi dalam penelitian ini melihat hubungan antara variabel independen dan variabel dependen dengan menggunakan analisis uji chi square. Penyajian data dalam penelitian ini menggunakan naratif Penyajian data dalam bentuk teks, dilakukan untuk mendeskripsikan atau memberikan penjelasan dari data yang telah disajikan dalam bentuk tabel. ${ }^{16}$

Analisa univariat digunakan untuk mendeskripsikan karakteristik dari variable indepen dan dependen. keseluruhan data yang ada dalam kuesioner diolah dan disajikan dalam bentuk tabel distribusi frekuensi. Analisa bivariat digunakan untuk melihat hubungan antara variabel independen dan variabel dependen dengan menggunakan analisis uji chi square. Melalui uji statistik chi square akan diperoleh nilai $\mathrm{p}$, dimana dalam penelitian ini digunakan tingkat kemaknaan sebesar 0,05 . Penelitian antara dua variabel dikatakan bermakna jika mempunyai nilai $\mathrm{p} \leq$ 0,05 yang berarti Ho ditolak dan Ha diterima dan dikatakan tidak bermakna jika mempunyai nila $\mathrm{p}>0,05$ yang berarti Ho diterima dan $\mathrm{Ha}$ ditolak.

Interpretasi data disajikan dalam bentuk narasi sehingga memudahkan pemahaman terhadap hasil penelitian, yaitu diungkapkan bahwa berdasarkan teori yang dapat dilihat Hubungan Kelas Ibu Hamil, Tingkat Ekonomi, dan Fasilitas Kesehatan, terhadap Motivasi Ibu Hamil dalam Melakukan Kunjungan ANC.

\section{Hasil}

\section{Analisis Univariat}

Berdasarkan hasil penelitian pada tabel 1 dapat diketahui bahwa bu hamil yang memiliki motivasi rendah ada sebanyak 26(52,0\%) oarng.Distribusi frekuensi kelas ibu hamil yang tidak baik ada sebanyak 26 (52,0\%) orang. Distribusi frekuensi bahwa ibu hamil yang tingkat ekonom < 1 juta ada sebanyak 31 $(62,0 \%)$ orang.Distribusi frekuensi bahwa 
tempat fasilitasi kesehatan yang buruk ada sebanyak $27(54.0 \%)$.

Tabel 1. Gambaran Kelas Ibu Hamil, Tingkat Ekonomi, Tempat Fasilitas Kesehatan Tahun

\begin{tabular}{lcc}
\hline \multicolumn{1}{c}{ Variabel } & $\begin{array}{c}\text { Frekuensi } \\
\text { (f) }\end{array}$ & $\begin{array}{c}\text { Presentasi } \\
(\mathbf{\%})\end{array}$ \\
\hline $\begin{array}{l}\text { Motivasi Ibu } \\
\quad \text { Rendah }\end{array}$ & 26 & $52,0 \%$ \\
$\quad$ Tinggi & 24 & $48,0 \%$ \\
$\begin{array}{l}\text { Kelas Ibu Hamil } \\
\quad \text { Terlaksana dengan } \\
\text { baik }\end{array}$ & 26 & $52,0 \%$ \\
$\quad$ Terlaksana dengan & 24 & $48,0 \%$ \\
$\quad$ baik & & \\
Tingkat Ekonomi & & \\
$\quad<1$ juta & 31 & $62,0 \%$ \\
$\quad>1$ juta & 19 & $38,0 \%$ \\
Tempat Fasilitas & & \\
Kesehatan & & \\
$\quad$ Fasilitas Baik & 27 & $54,0 \%$ \\
$\quad$ Fasilitas buruk & 23 & $46,0 \%$ \\
\hline 2017 & &
\end{tabular}

Berdasarkan tabel 2 tergambar di peroleh dari total $26(100 \%)$ bahwa ada sebanyak 23 $(88,5 \%)$ kelas ibu hamil yang tidak terlaksana dengan baik, sedangkkan $3(11,5 \%)$ kelas ibu hamil yang tidak terlaksana dengan baik tetapi memiliki motivasi yang tinggi. Hasil uji statistik diperoleh nilai $\mathrm{p}=0,000$ berarti nilai $\mathrm{p}<0,05$ sehingga dapat disimpulkan ada hubungan yang signifikan antara kelas ibu hamil dengan motivasi ibu.

Hasil analisa diperoleh nilai OR 53,667 dapat disimpulkan bahwa kelas ibu hamil yang tidak terlaksana dengan baik mempunyai peluang 53,667 kali beresiko mengalami dibandigkan dengan kelas ibu hamil yang terlaksana dengan baik dalam motivasi ibu. Berdasarkan tabel 2 diperoleh dari total sebanyak 31 (100\%), ada sebanyak $22(71,0 \%)$ ibu hamil yang tingkat ekonominya $<1$ juta memiliki motivasi yang rendah, sedangkan 9 $(29,0 \%)$ ibu hamil yang tingkat ekonominya < juta tetapi memiliki motivasi yang tinggi.

Hasil uji statistik diperoleh nilai $\mathrm{P}=0,001$ berarti nilai $p<0,05$ sedingga dapat disimpulkan ada hubungan yang signifikan antara tingkat ekonomi dengan motivasi ibu. Hasil analisa diperoleh nilai OR 9,167 dapat disimpulkan bahwa ibu hamil yang tingkat ekonominya < 1 juta mempunyai peluang 9,167 kali beresiko mempunyai motivasi yang rendah dibandingkan dengan ibu hamil yang tingkat ekonominya $>1$ juta.

Tabel 2. Tabel 2 Hubungan Kelas Ibu Hamil, Tingkat Ekonomi, Tempat Fasilitas Kesehatan dengan Motivasi Ibu dalam Melakukan Kunjungan ANC di Puskesmas Cibadak Desa Malabar Tahun 2017.

\begin{tabular}{|c|c|c|c|c|c|c|}
\hline \multirow{3}{*}{ Variabel } & \multicolumn{4}{|c|}{ Motivasi Ibu } & \multirow{3}{*}{$P^{\text {Value }}$} & \multirow{3}{*}{ OR } \\
\hline & \multicolumn{2}{|c|}{ Anemia sedang } & \multicolumn{2}{|c|}{ Anemia Ringan } & & \\
\hline & $\mathbf{F}$ & $\%$ & $\mathbf{F}$ & $\%$ & & \\
\hline \multicolumn{7}{|l|}{ Kelas Ibu Hamil } \\
\hline \multirow{2}{*}{$\begin{array}{l}\text { Tidak terlaksana dengan } \\
\text { baik }\end{array}$} & 23 & 88,5 & 3 & 11,5 & \multirow{3}{*}{53,667} & \multirow{3}{*}{0.000} \\
\hline & & & & & & \\
\hline Terlaksana dengan baik & 3 & 12,5 & 21 & 87,5 & & \\
\hline \multicolumn{7}{|l|}{ Tingkat Ekonomi } \\
\hline$<1$ juta & 22 & 71,0 & 9 & 29,0 & \multirow[b]{2}{*}{9,167} & \multirow[b]{2}{*}{0,001} \\
\hline$>1$ juta & 4 & 21,1 & 15 & 78,9 & & \\
\hline \multicolumn{7}{|l|}{$\begin{array}{l}\text { Tempat Fasilitas } \\
\text { Kesehatan }\end{array}$} \\
\hline $\begin{array}{l}\text { Buruk } \\
\text { Baik }\end{array}$ & $\begin{array}{c}7 \\
26\end{array}$ & $\begin{array}{l}30,4 \\
52,0\end{array}$ & $\begin{array}{l}16 \\
24\end{array}$ & $\begin{array}{l}69,6 \\
48,0\end{array}$ & 5,429 & 0,005 \\
\hline
\end{tabular}




\section{Pembahasan}

\section{Hubungan Kelas Ibu Hamil dengan Motivasi}

Hasil uji statistic diperoleh nilai $\mathrm{P}=0,000$ berarti nilai $\mathrm{p}<0,05$, sehingga dapat disimpulkan ada hubungan yang signifikan antara kelas ibu hamil dengan motivasi ibu. Hasil analisa diperoleh nilai OR 53,667 dapat disimpulkan bahwa kelas ibu hamil yang tidak terlaksana dengan baik mempunyai peluang 53,667 kali beresiko mengalami dibandingkan dengan kelas ibu hamil yang terlaksana dengan baik dalam motivasi ibu

Hal ini sejalan dengan hasil penelitian yang dilakukan Hj. Erni Setiawati, M Mukhtar, Hj. Norhayati. Maslani di dapat hasil uji ChiSquare pada $(\alpha) 0,05$ didapatkan nilai $\rho=$ 0,001 atau lebih kecil dari $(\alpha)$ sehingga Ho ditolak, artinya ada hubungan antara kelas ibu hamil terhadap pelaksanaan senam hamil. Kelas ibu hamil adalah kelompok belajar ibuibu hamil dengan umur kehamilan antara 20 minggu s/d 32 minggu dengan jumlah peserta maksimal 10 orang. Di kelas ini ibu hamil akan belajar bersama, diskusi dan tukar pengalaman tentang kesehatan ibu dan anak secara menyeluruh dan sistematis serta dapat dilaksanakan secara terjadwal dan berkesinambungan. Peneliti berasumsi kelas ibu hamil yang baik sangat berpengaruh terhadap motivasi ibu hamil ada kunjungan ANC karena ibu hamil akan memiliki motivasi yang tinggi.

\section{Hubungan Tingkat Ekonomi dengan Motivasi Ibu}

Hasil uji statistic diperoleh nilai $\mathrm{P}=0,001$ berarti nilai $\mathrm{p}<0,05$, sehingga dapat disimpulkan ada hubungan yang signifikan antara tingkat ekonomi dengan motivasi ibu. Hasil analisa diperoleh nilai OR 9,167 dapat disimpulkan bahwa ibu hamil yang tingkat ekonominya < 1jt mempunyai peluang 9,167 kali beresiko mempunyai motivasi yang rendah dibandingkan dengan ibu hamil yang tingkat ekonominya $>1 \mathrm{jt}$.

Hasil ini sejalan dengan hasil penelitian yang di lakukan Astuti Febiana Mustofa di dapatkan hasil analisis dengan menggunakan chi-square dengan taraf kepercayaan $95 \%$, diperoleh $\rho$ value 0,025 ( $\rho$ value $<0,005$ ) dengan contingency coefficient (CC) sebesar 0,468. Sehingga dapat diketahui bahwa ada hubungan antara tingkat ekonomi dengan patuhnya terhadap kunjungan ANC saat kehamilan, dengan tingkat keeratan hubungan kategori sedang.

Tingkat ekonomi itu berasal dari kata oikinomia dari bahasa yunani, kata tersebut menrupakan turunan dari dua kata yakni oikos dan nomo. Oikos berarti rumah tangga, sedangkan nomor bearti mengatur, jadi arti oikonomia adalah mengatur rumah tangga. Peneliti berasumsi tingkat ekonomi sangat mempengaruhi motivasi ibu hamil untuk rutin memeriksakan kehamilannya pada petugas kesehatan. ${ }^{17}$

\section{Hubungan Tempat Fasilitas Kesehatan dengan Motivasi Ibu}

Hasil uji statistik diperoleh nilai $\mathrm{P}=0,005$ berarti nilai $p<0,05$, sehingga dapat disimpulkan ada hubungan yang signifikan antara tempat fasilitas kesehatan dengan motivasi ibu. Hasil analisa diperoleh nilai OR 5,429dapat disimpulkan bahwa ibu hamil yang mendapatkan tempat fasilitas yang buruk mempunyai peluang 5,429 kali beresiko mempunyai motivasi yang rendah dibandingkan dengan ibu hamil yang mendapatkan tempat fasilitas kesehatan yang baik Hasil ini sejalan dengan hasil penelitian yang di lakukan Diah Rahayu, di dapatkan hasil analisis dengan menggunakan uji chi square yang diperoleh $\rho$ value 0,033 ( $\rho$ value $<0,005$ ), sehingga dapat disimpulkan ada hubungan yang bermakna antara tempat fasilitas kesehatan dengan komitmen kerja bidan.

Fasilitas kesehatan adalah fasilitas yang berhubungan dengan tempat ibu mendapatkan pelayanan kesehatan untuk memeriksa kehamilannya sampai ibu dapat melahirkan dengan aman, Tersedianya fasilitas kesehatan yang memadai dengan jarak yang mudah terjangkau akan memberi kemudahan bagi ibu hamil untuk sering memeriksakan kehamilannya dan untuk mendapatkan penanganan atau petunjuk kepada ibu dan keluarga tentang pemanfaatan sarana kesehatan seperti rumah bersalin, polindes, PKM dan fasilitas kesehatan lainnya yang sangat penting dan aman bagi kehamilan. Peneliti berasumsi motivasi ibu hamil terhadap pencegahan kejadian rupture perineum sangat berperan penting dalam psikososial seseorang jika motivasi ibu hamil tidak baik terhadap 
kehamilannya maka akan mengakibatkan rupture perineum pada persalinan normal.

\section{Kesimpulan}

Berdasarkan penelitian dapat ditarik kesimpulan, sebagian besar ibu hamil memiliki motivasi yang rendah dalam melakukan kunjungan ANC di Puskesmas Cibadak Desa Malabar Tahun 2017, Ada hubungan antara kelas ibu hamil terhadap motivasi ibu hamil dalam melakukan kunjungan ANC di Puskesmas Cibadak Desa Malabar Tahun 2017, Ada hubungan antara tingkat ekonomi terhadap motivasi ibu hamil dalam melakukan kunjungan ANC di Puskesmas Cibadak Desa Malabar Tahun 2017, dan Ada hubungan antara tempat fasilitas kesehatan terhadap motivasi ibu hamil dalam melakukan kunjungan ANC di Puskesmas Cibadak Desa Malabar Tahun 2017.

\section{Saran}

Bagi institusi pendidikan diharapkan menambah wawasan referensi pustaka untuk ilmu pengetahuan bagi dosen dan mahasiswa.

Bagi ibu hamil meningkatkan motivasi ibu untuk melakukan kunjunga ANC.

Bagi peneliti selanjutnya diharapkan dapat meneliti lebih komprehensif dengan menambah variabel indipenden yang berpariasi dan belum diteliti. Sehingga ilmu yang didapat lebih luas mengenai motivasi kunjungan ANC.

\section{Daftar Pustaka}

1. Prawirohardjo S. Asuhan Kebidanan. Jakarta: PT Bina Pustaka; 2014.

2. Kemenkes. Rencana Strategi Kementrian Kesehatan. Jakarta: Kementrian Kesehtan RI; 2015-2019.

3. Wiknjosatro H. Ilmu Kebidanan. Jakarta: Yayasan Bina Pustaka Sarwono Prawirohardjo; 2010.

4. Depkes RI. Kunjungan antenatal care. Infodatin-ibu-pdf, diakses pada bulan Februari 2017, www.depkes.go.id>infodatin-ibu; 2013.

5. Lebak. profil dinas kesehatan kabupaten lebak,Diakses pada bulan Februari 2017, https://dinkes.bantenprov.go.id; 2013.

6. Ayudiyah. Hubungan Tentang Kelas Ibu Hamil dengan motivasi dengan mengikuti kelas Ibu Hamil di Puskesmas 2 mandiraja Kabupaten Banjarnegara. [skripsi]. 2008.

7. Yeyeh A. Asuhan Kebidanan I Kehamilan. Jakarta: CV Trans Info Media; 2009.

8. Bimo W. Pengantar Fisikolog umum. Yogyakarta: CV Andi; 2010.
9. Astuti F. Hubungan dukungan keluarga, Tingkat Ekonomi terhadap Kunjungan ANC. [jurnal kesmas]. Depok: UI; 2009.

10. Rahayu D..Hubungan peran petugas kesehatan, tempat fasilitas kesehata, terhadap kunjungan ANC. [jurnal kesmas]UI. Depok. 2010.

11. Erni S.[jurnal kedokteran]. Hubungan kelas ibu hamil terhadap kunjungan ANC. UI . Depok.; 2010.

12. Sugiyono D. Metode Peneitian kunatitatif, kualitatif dan R \& D. Bandung: Alfabeta; 2012.

13. Notoatmodjo. Metode Penelitian kesehatan. Jakart: Rineka Cipta; Jakarta; 2010.

14. Nova O. Sistematik Penulisan Karya Ilmiah. Yogyakarta; Deepublish; 2015.

15. Nursalam. Konsep \& Penerapan Metode Penelitian Ilmu Keperawatan Pendoman Ilmu Keperawatan, Pendoman Skripsi, Tesis dan Instrumen Penelitian Keperawatan. Jakarta: Salemba Medika; 2007.

16. Burhan N. Statistik Terapan Penelitian Ilmuilmu Sosial. Yogyakarta: Universitas Gajahmada; 2007.

17. Kartono. Perilaku pada manusia. Jakarta: ISBN; 2007. 